\title{
Outcomes of basilar artery occlusion in patients aged 75 years or older in the Basilar Artery International Cooperation Study
}

\author{
Mervyn D. I. Vergouwen - Annette Compter • David Tanne $\cdot$ Stefan T. Engelter • \\ Heinrich Audebert $\cdot$ Vincent Thijs $\cdot$ Gabriel de Freitas $\cdot$ Ale Algra \\ L. Jaap Kappelle $\cdot$ Wouter J. Schonewille
}

Received: 1 February 2012/Revised: 23 March 2012/Accepted: 25 March 2012/Published online: 18 April 2012

(C) The Author(s) 2012. This article is published with open access at Springerlink.com

\begin{abstract}
Patients with an acute basilar artery occlusion (BAO) have a high risk of long-lasting disability and death. Only limited data are available on functional outcome in elderly patients with BAO. Using data from the Basilar Artery International Cooperation Study, we aimed to determine outcomes in patients $\geq 75$ years. Primary outcome measure was poor functional outcome (modified Rankin scale score 4-6). Secondary outcomes were death, insufficient vessel recanalization (defined as thrombolysis in myocardial infarction score 0-1) and symptomatic intracranial hemorrhage (SICH). Patients were divided into four age-groups, based on quartiles: 18-54, 55-64, 65-74,
\end{abstract}

On behalf of the BASICS Study Group.

Electronic supplementary material The online version of this article (doi:10.1007/s00415-012-6498-2) contains supplementary material, which is available to authorized users.

M. D. I. Vergouwen $(\bowtie) \cdot A$. Compter · A. Algra ·

L. Jaap Kappelle · W. J. Schonewille

Department of Neurology and Neurosurgery, UMC Utrecht

Stroke Center, Rudolf Magnus Institute of Neurosciences,

University Medical Center Utrecht, Heidelberglaan 100,

3584 CX Utrecht, The Netherlands

e-mail: M.D.I.Vergouwen@umcutrecht.nl

D. Tanne

Department of Neurology, Stroke Center, Chaim Sheba Medical

Centre, Tel Aviv University, Tel-Hashomer, Israel

S. T. Engelter

Department of Neurology, University Hospital Basel,

Basel, Switzerland

H. Audebert

Center for Stroke Research, Charité University Medicine Berlin,

Campus Benjamin, Franklin, Germany and $\geq 75$ years. Outcomes were compared between patients $\geq 75$ years and patients aged $18-54$ years. Risk ratios with corresponding $95 \%$ confidence intervals (CI) were calculated and Poisson regression analyses were performed to calculate adjusted risk ratios (aRR). We included 619 patients [18-54 years $n=153(25 \%), 55-64$ years $n=133 \quad(21 \%), \quad 65-74$ years $n=171 \quad(28 \%)$, and $\geq 75$ years $n=162(26 \%)$ ]. Compared with patients aged $18-54$ years, patients $\geq 75$ years were at increased risk of poor functional outcome [aRR $1.33(1.14-1.55)]$ and death [aRR 2.47 (1.75-3.51)]. Nevertheless, 35/162 (22\%, $95 \%$ CI $15-28 \%$ ) of patients $\geq 75$ years had good functional outcome. No significant differences between age groups were observed for recanalization rate and incidence of SICH. Although patients $\geq 75$ years with BAO have an increased risk of poor outcome compared with younger patients, a substantial group of patients $\geq 75$ years survives with a good functional outcome.

V. Thijs

Department of Neurology, University Hospitals Leuven and Vesalius Research Centre, VIB, Leuven, Belgium

G. de Freitas

Department of Neurology, University of Rio de Janeiro, Rio de Janeiro, Brazil

A. Algra

Julius Center for Health Sciences and Primary Care,

University Medical Center, Utrecht, The Netherlands

W. J. Schonewille

Department of Neurology, St. Antonius Hospital,

Nieuwegein, The Netherlands 
Keywords Basilar artery occlusion - Age . Recanalization $\cdot$ Outcome $\cdot$ Mortality

\section{Introduction}

Patients with an acute basilar artery occlusion (BAO) have a high risk of long-lasting disability and death $[1,2]$. Although higher age, analyzed as a continuous variable, has been associated with poor functional outcome after $\mathrm{BAO}$, only limited data are available on functional outcome in elderly patients [3-8]. One small case series suggested that all patients $\geq 75$ years have poor functional outcome [6]. In another study, the eldest surviving patient in whom recanalization was successful was 63-year-old [3]. We analysed data from the Basilar Artery International Cooperation Study (BASICS) to determine outcomes in patients with $\mathrm{BAO} \geq 75$ years.

\section{Methods}

BASICS is a prospective, observational, registry of 619 consecutive patients $\geq 18$ years with an acute symptomatic BAO [2,9]. The protocol was approved by the ethics committee of the University Medical Center Utrecht, the Netherlands. Embolic BAO was defined as complete recanalization on follow-up and no indication of dissection, or maximum deficit from onset and cardiac or vertebral source of embolism, or maximum deficit from onset with complete absence of other atherosclerotic cerebrovascular lesions. Atherosclerotic BAO was defined as known symptomatic basilar artery stenosis $(>50 \%)$ prior to occlusion, or residual stenosis after recanalization and no evidence of cardiac or vertebral artery source of embolism, or prior TIAs or stroke in the basilar artery territory and no evidence of cardiac or vertebral artery source of embolism. Dissections were not predefined, but scored according to the investigators.

Primary outcome was poor functional outcome after 1 month [predefined as modified Rankin scale (mRS) score 4-6]. Secondary outcomes were death, insufficient vessel recanalization [defined as thrombolysis in myocardial infarction (TIMI) score 0-1] and symptomatic intracranial hemorrhage (SICH). We also investigated if our conclusions changed if poor functional outcome was defined as an mRS of 3-6. SICH was not predefined by the registry, and the reporting of SICH was done on the basis of each investigator's judgment. For the purpose of this study, patients were divided into four age-groups, based on quartiles: $18-54,55-64,65-74$, and $\geq 75$ years. Outcomes were compared between patients $\geq 75$ years and patients aged 18-54 years. Risk ratios (RR) and corresponding $95 \%$ confidence intervals (CI) were calculated. Variables that affected the crude risk ratio most were used simultaneously in Poisson regression analyses to calculate adjusted risk ratios (aRR) [2]. Missing baseline data $(<5 \%$ for each variable) were imputed with regression imputation [10]. Finally, we explored the incidence of poor functional outcome in patients $75-79,80-84,85-89$, and 90 years or older.

\section{Results}

Baseline characteristics are listed in Table 1. In total, 162 patients ( $26 \%$ of total cohort) were $\geq 75$ years. In this group of patients, the most common cause of stroke was embolism and $64 \%$ had an NIHSS score $>20$. Treatment of any kind was initiated in 148 patients (91\%).

Modified Rankin Scale scores for all age groups are presented in Fig. 1. Patients $\geq 75$ years had a higher risk of poor functional outcome [aRR 1.33 (1.14-1.55), Table 2] and death [aRR 2.47 (1.75-3.51), Table 3] than patients aged 18-54 years. Nevertheless, 35 patients $(22 \%, 95 \%$ CI $15-28 \%)$ of those $\geq 75$ years had a good functional outcome. No significant differences between age groups were observed for insufficient recanalization [patients $\geq 75$ vs. $18-54$ years aRR 1.69 (0.95-3.03)] and $\mathrm{SICH}$ [patients $\geq 75$ vs. $18-54$ years RR 1.77 (0.77-4.06)]. Since SICH occurred in only $42(7 \%)$ patients, no further analyses were performed for this outcome measure.

If poor functional outcome was defined as an mRS of $3-6$, the proportion of patients with poor functional outcome in each age group was 108/153 (71 \%) in patients 18-54 years of age, 101/133 (76\%) in patients 55-64 years, 142/171 (83\%) in patients 65-74 years, and $137 / 162(85 \%)$ in patients $\geq 75$ years. Also when this definition was used, patients $\geq 75$ years had a higher risk of poor functional outcome [aRR 1.21 (1.07-1.36)] than patients aged $18-54$ years.

Baseline characteristics of patients $\geq 75$ years and their relationship with functional outcome are shown in Table 4 . The following variables were associated with an increased risk of poor functional outcome after 1 month: male sex (RR 1.18, $95 \%$ CI 1.00-1.38), location of occlusion (middle third vs. distal third: RR 1.21, $95 \% \mathrm{CI}$ 1.02-1.44), NIHSS score $>20$ on presentation (RR 1.36, $95 \%$ CI 1.10-1.67), type of treatment (no treatment vs. intra-arterial thrombolytic therapy (IAT) only: RR 1.32, $95 \%$ CI 1.15-1.52), SICH (RR 1.21, $95 \%$ CI 1.03-1.43), and insufficient recanalization (RR $1.38,95 \%$ CI 1.07-1.77). 
Table 1 Baseline characteristics according to age group

\begin{tabular}{|c|c|c|c|c|c|}
\hline Variable & $\begin{array}{l}\text { All patients } \\
n=619\end{array}$ & $\begin{array}{l}18-54 \text { years } \\
n=153\end{array}$ & $\begin{array}{l}55-64 \text { years } \\
n=133\end{array}$ & $\begin{array}{l}65-74 \text { years } \\
n=171\end{array}$ & $\begin{array}{l}\geq 75 \text { years } \\
n=162\end{array}$ \\
\hline Male sex & $390(63 \%)$ & $94(61 \%)$ & $105(79 \%)$ & $116(68 \%)$ & $75(46 \%)$ \\
\hline Hypertension & $383(62 \%)$ & $41(27 \%)$ & $87(65 \%)$ & $133(78 \%)$ & $122(75 \%)$ \\
\hline Diabetes mellitus & $135(22 \%)$ & $13(8 \%)$ & $31(23 \%)$ & $49(29 \%)$ & $42(26 \%)$ \\
\hline Hyperlipidemia & $167(27 \%)$ & $30(20 \%)$ & $45(34 \%)$ & $55(32 \%)$ & $37(23 \%)$ \\
\hline Atrial fibrillation & $133(21 \%)$ & $3(2 \%)$ & $20(15 \%)$ & $42(25 \%)$ & $68(42 \%)$ \\
\hline Coronary artery disease & $109(18 \%)$ & $12(8 \%)$ & $21(16 \%)$ & $35(20 \%)$ & $41(25 \%)$ \\
\hline \multicolumn{6}{|c|}{ Location of basilar artery occlusion } \\
\hline Distal third & $202(33 \%)$ & $42(27 \%)$ & $30(23 \%)$ & $55(32 \%)$ & $75(46 \%)$ \\
\hline Middle third & $143(23 \%)$ & $37(24 \%)$ & $29(22 \%)$ & $46(27 \%)$ & $31(19 \%)$ \\
\hline Proximal third & $274(44 \%)$ & $74(48 \%)$ & $74(56 \%)$ & $70(41 \%)$ & $56(35 \%)$ \\
\hline Median NIHSS score (IQR) & $22(12-30)$ & $20(9-30)$ & $20(12-30)$ & $22(13-28)$ & $25(16-30)$ \\
\hline NIHSS score $>20$ & $336(54 \%)$ & $73(48 \%)$ & $66(50 \%)$ & $93(54 \%)$ & $104(64 \%)$ \\
\hline \multicolumn{6}{|l|}{ Type of treatment } \\
\hline Antithrombotics & $183(30 \%)$ & $47(31 \%)$ & $33(25 \%)$ & $52(30 \%)$ & $51(31 \%)$ \\
\hline IV tPA or IV tPA/IAT & $121(20 \%)$ & $25(16 \%)$ & $37(28 \%)$ & $24(14 \%)$ & $35(22 \%)$ \\
\hline IAT only & $288(47 \%)$ & $78(51 \%)$ & $59(44 \%)$ & $89(52 \%)$ & $62(38 \%)$ \\
\hline No treatment & $27(4 \%)$ & $3(2 \%)$ & $4(3 \%)$ & $6(4 \%)$ & $14(9 \%)$ \\
\hline \multicolumn{6}{|l|}{ Time to treatment } \\
\hline $0-3 \mathrm{~h}$ & $179(29 \%)$ & $41(27 \%)$ & $39(29 \%)$ & $49(29 \%)$ & $50(31 \%)$ \\
\hline $4-6 \mathrm{~h}$ & $190(31 \%)$ & $45(29 \%)$ & $37(28 \%)$ & $58(34 \%)$ & $50(31 \%)$ \\
\hline $7-9 \mathrm{~h}$ & $84(14 \%)$ & $22(14 \%)$ & $19(14 \%)$ & $26(15 \%)$ & $17(10 \%)$ \\
\hline $10-12 \mathrm{~h}$ & $57(9 \%)$ & $14(9 \%)$ & $14(11 \%)$ & $16(9 \%)$ & $13(8 \%)$ \\
\hline $13-24 \mathrm{~h}$ & $55(9 \%)$ & $17(11 \%)$ & $15(11 \%)$ & $9(5 \%)$ & $14(9 \%)$ \\
\hline$>24 \mathrm{~h}$ & $27(4 \%)$ & $11(7 \%)$ & $5(4 \%)$ & $7(4 \%)$ & $4(2 \%)$ \\
\hline \multicolumn{6}{|l|}{ Cause of stroke } \\
\hline Embolism & $224(36 \%)$ & $42(27 \%)$ & $38(29 \%)$ & $59(35 \%)$ & $85(52 \%)$ \\
\hline Atherosclerosis & $215(35 \%)$ & $39(25 \%)$ & $57(43 \%)$ & $72(42 \%)$ & $47(29 \%)$ \\
\hline Dissection & $32(5 \%)$ & $24(16 \%)$ & $5(4 \%)$ & $3(2 \%)$ & $0(0 \%)$ \\
\hline Other & $6(1 \%)$ & $2(1 \%)$ & $1(1 \%)$ & $2(1 \%)$ & $1(1 \%)$ \\
\hline Unknown & $142(23 \%)$ & $44(29 \%)$ & $30(23 \%)$ & $31(18 \%)$ & $27(17 \%)$ \\
\hline
\end{tabular}

NIHSS national institutes of health stroke scale, IQR interquartile range, $I V$ intravenous, $t P A$ tissue plasminogen activator, IAT any intra-arterial treatment (either intra-arterial tPA, mechanical clot disruption, or both)

Fig. 1 Modified Rankin scale scores according to age group. $m R S$ modified Rankin scale score

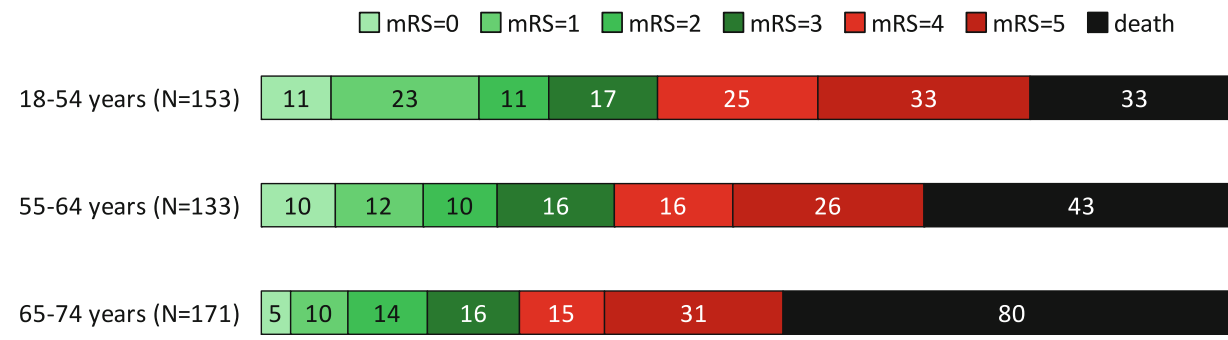

$\geq 75$ years $(\mathrm{N}=162)$

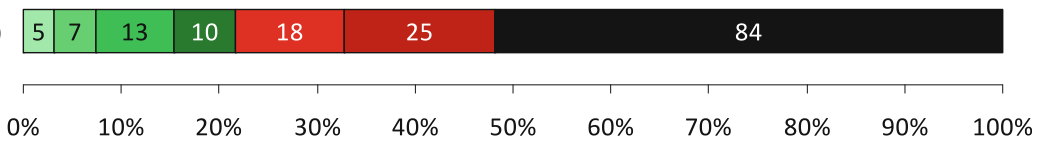

The proportion of patients with poor functional outcome in age subgroups $\geq 75$ years was as follows: 64/82 (78\%) in patients $75-79$ years of age, $40 / 49(82 \%)$ in patients

$80-84$ years, $16 / 23(70 \%)$ in patients $85-89$ years, and $7 / 8$ $(88 \%)$ in patients 90 years or older. The oldest patient with good functional outcome was 91 years of age, despite 
Table 2 Poor functional outcome (mRS 4-6) according to age-group

\begin{tabular}{|c|c|c|c|c|}
\hline & $18-54$ years $^{\mathrm{a}}$ & 55-64 years & $65-74$ years & $\geq 75$ years \\
\hline Total & $153(25 \%)$ & $133(21 \%)$ & $171(28 \%)$ & $162(26 \%)$ \\
\hline Poor outcome & $91 / 153(60 \%)$ & $85 / 133(64 \%)$ & 126/171 (74\%) & $127 / 162(78 \%)$ \\
\hline Unadjusted & 1 & $1.08(0.90-1.29)$ & $1.24(1.06-1.45)$ & $1.32(1.13-1.54)$ \\
\hline \multicolumn{5}{|l|}{ Adjusted } \\
\hline Male sex & 1 & $1.06(0.88-1.28)$ & $1.23(1.05-1.45)$ & $1.33(1.14-1.55)$ \\
\hline Location of occlusion & 1 & $1.06(0.89-1.27)$ & $1.26(1.08-1.47)$ & $1.37(1.18-1.60)$ \\
\hline NIHSS & 1 & $1.06(0.90-1.25)$ & $1.22(1.06-1.41)$ & $1.23(1.06-1.41)$ \\
\hline Time to treatment (h) & 1 & $1.08(0.90-1.30)$ & $1.26(1.07-1.49)$ & $1.33(1.13-1.56)$ \\
\hline Type of treatment & 1 & $1.07(0.89-1.29)$ & $1.24(1.05-1.46)$ & $1.32(1.12-1.55)$ \\
\hline 3 factors $^{b}$ & 1 & $1.05(0.89-1.24)$ & $1.24(1.07-1.43)$ & $1.28(1.11-1.48)$ \\
\hline 5 factors $^{c}$ & 1 & $1.06(0.90-1.25)$ & $1.28(1.10-1.49)$ & $1.33(1.14-1.55)$ \\
\hline
\end{tabular}

${ }^{a}$ Reference group. Data are number (\%) or risk ratio (95\% CI)

b Adjustment for national institutes of health stroke scale (NIHSS) score, sex, and location of occlusion

c Adjustment for NIHSS score, sex, location of occlusion, time to treatment, and type of treatment

Table 3 Mortality according to age group

\begin{tabular}{|c|c|c|c|c|}
\hline & $18-54$ years $^{\mathrm{a}}$ & 55-64 years & $65-74$ years & $\geq 75$ years \\
\hline Total & $153(25 \%)$ & $133(21 \%)$ & $171(28 \%)$ & $162(26 \%)$ \\
\hline Mortality & $33 / 153(22 \%)$ & $43 / 133(32 \%)$ & $80 / 171(47 \%)$ & $84 / 162(52 \%)$ \\
\hline Unadjusted & 1 & $1.50(1.02-2.21)$ & $2.17(1.54-3.05)$ & $2.40(1.72-3.37)$ \\
\hline \multicolumn{5}{|l|}{ Adjusted } \\
\hline Male sex & 1 & $1.48(1.002-2.19)$ & $2.16(1.53-3.04)$ & $2.43(1.73-3.40)$ \\
\hline Location of occlusion & 1 & $1.47(0.998-2.16)$ & $2.22(1.58-3.11)$ & $2.55(1.83-3.56)$ \\
\hline NIHSS & 1 & $1.46(1.008-2.12)$ & $2.13(1.55-2.94)$ & $2.16(1.57-2.98)$ \\
\hline Time to treatment $(\mathrm{h})$ & 1 & $1.56(1.04-2.35)$ & $2.28(1.59-3.27)$ & $2.41(1.68-3.46)$ \\
\hline Type of treatment & 1 & $1.55(1.03-2.34)$ & $2.24(1.56-3.21)$ & $2.42(1.68-3.47)$ \\
\hline 3 factors $^{b}$ & 1 & $1.47(1.02-2.12)$ & $2.22(1.61-3.05)$ & $2.31(1.68-3.17)$ \\
\hline 5 factors ${ }^{c}$ & 1 & $1.56(1.05-2.31)$ & $2.41(1.71-3.39)$ & $2.47(1.75-3.51)$ \\
\hline
\end{tabular}

${ }^{a}$ Reference group. Data are number (\%) or risk ratio (95\% CI)

b Adjustment for national institutes of health stroke scale (NIHSS) score, sex and location of occlusion

c Adjustment for NIHSS score, sex, location of occlusion, time to treatment, and type of treatment

an NIHSS score of 21 on admission. This patient was treated with intravenous recombinant tissue plaminogen activator (rtPA) only, and had an mRS score of 2 at 1 month follow-up.

\section{Discussion}

The BASICS study shows that patients $\geq 75$ years with BAO have an increased risk of poor functional outcome and death compared with younger patients, despite comparable recanalization rates. In contrast with a small previous study [6], our data show that a substantial group of patients $\geq 75$ years survives with good functional outcome.

Previously, it has been suggested that the increased risk of poor functional outcome in elderly patients resulted from a higher prevalence of atherosclerotic occlusions and consequently lower recanalization rates [3]. However, in our study population patients $\geq 75$ years were more likely to have an embolic rather than an atherosclerotic cause of BAO, mainly due to a higher prevalence of atrial fibrillation. Patients $\geq 75$ years with an embolic cause of BAO had a similar risk of poor functional outcome compared with patients in this age group with an atherosclerotic cause of BAO. Sufficient recanalization was achieved in $71 \%$ of patients in this age group.

In patients $\geq 75$ years, several baseline- and treatmentrelated characteristics were associated with an increased risk of poor functional outcome. A recent large case series of patients with $\mathrm{BAO}$, in which only a minority of patients was $\geq 75$ years, identified similar risk factors for poor functional outcome and death [7]. 
Table 4 Characteristics of patients $\geq 75$ years and risk of poor functional outcome
${ }^{\text {a }}$ Distal occlusion was taken as reference and is recorded under "characteristic absent"

b IAT only was taken as reference and is recorded under "characteristic absent"

c $0-3 \mathrm{~h}$ was taken as reference and is recorded under

"characteristic absent"

d Atherosclerosis was taken as reference and is recorded under "characteristic absent"

\begin{tabular}{|c|c|c|c|}
\hline \multirow[t]{2}{*}{ Variable } & \multicolumn{2}{|c|}{ Risk of poor functional outcome (mRS 4-6) } & \multirow[t]{2}{*}{$\mathrm{RR}(95 \% \mathrm{CI})$} \\
\hline & Characteristic present & Characteristic absent & \\
\hline Male sex & $64 / 75(85 \%)$ & $63 / 87(72 \%)$ & $1.18(1.00-1.38)$ \\
\hline Hypertension & $98 / 122(80 \%)$ & $29 / 40(73 \%)$ & $1.11(0.90-1.37)$ \\
\hline Diabetes mellitus & $29 / 42(69 \%)$ & $98 / 120(82 \%)$ & $0.85(0.68-1.05)$ \\
\hline Hyperlipidemia & $27 / 37(73 \%)$ & $100 / 125(80 \%)$ & $0.91(0.74-1.13)$ \\
\hline Atrial fibrillation & $57 / 68(84 \%)$ & $70 / 94(74 \%)$ & $1.13(0.96-1.32)$ \\
\hline Coronary artery disease & $35 / 41(85 \%)$ & $92 / 121(76 \%)$ & $1.12(0.96-1.32)$ \\
\hline \multicolumn{4}{|l|}{ Location of basilar artery occlusion ${ }^{\mathrm{a}}$} \\
\hline Proximal third & $43 / 56(77 \%)$ & $56 / 75(75 \%)$ & $1.03(0.85-1.25)$ \\
\hline Middle third & $28 / 31(90 \%)$ & $56 / 75(75 \%)$ & $1.21(1.02-1.44)$ \\
\hline NIHSS score $>20$ & $90 / 104(87 \%)$ & $37 / 58(64 \%)$ & $1.36(1.10-1.67)$ \\
\hline \multicolumn{4}{|l|}{ Type of treatment ${ }^{\mathrm{b}}$} \\
\hline Antithrombotics & $38 / 51(75 \%)$ & $47 / 62(76 \%)$ & $0.98(0.79-1.22)$ \\
\hline IV tPA or IV tPA/IAT & $28 / 35(80 \%)$ & $47 / 62(76 \%)$ & $1.06(0.85-1.31)$ \\
\hline No treatment & $14 / 14(100 \%)$ & $47 / 62(76 \%)$ & $1.32(1.15-1.52)$ \\
\hline \multicolumn{4}{|l|}{ Time to treatment ${ }^{\mathrm{c}}$} \\
\hline $4-6 \mathrm{~h}$ & $35 / 50(70 \%)$ & $38 / 50(76 \%)$ & $0.92(0.73-1.17)$ \\
\hline $7-9 \mathrm{~h}$ & $13 / 17(76 \%)$ & $38 / 50(76 \%)$ & $1.01(0.74-1.37)$ \\
\hline$\geq 10 \mathrm{~h}$ & $27 / 31(87 \%)$ & $38 / 50(76 \%)$ & $1.15(0.93-1.41)$ \\
\hline \multicolumn{4}{|l|}{ Cause of stroke } \\
\hline Embolism $^{\mathrm{d}}$ & $65 / 85(76 \%)$ & $38 / 47(81 \%)$ & $0.95(0.79-1.14)$ \\
\hline Symptomatic intracranial hemorrhage & $14 / 15(93 \%)$ & $113 / 147(77 \%)$ & $1.21(1.03-1.43)$ \\
\hline Insufficient recanalization & $18 / 20(90 \%)$ & $32 / 49(65 \%)$ & $1.38(1.07-1.77)$ \\
\hline
\end{tabular}

The strength of this study is that BASICS was a prospective registry of consecutive patients, and therefore our results are representative for daily practice. A limitation of this study is that this was a post hoc analysis of non-randomized data, and therefore the data regarding treatmentdependent outcomes are prone to bias. Due to the prospective collection of detailed data, we were able to perform Poisson regression analyses to adjust for important confounding baseline characteristics.

We conclude that a substantial group of elderly patients survives with a good functional outcome. This study cannot answer the question which treatment option is superior in elderly patients, nor can it define an upper age limit above which treatment is no longer effective. These and other questions may be answered in the recently started BASICS trial in which patients with $\mathrm{BAO}$ of up to 85 years of age are randomized between intravenous thrombolysis (IVT) alone vs. IVT followed by additional intra-arterial therapy (http://www.trialregister.nl/trialreg/admin/rctview.asp?TC= 2617; accessed February 1, 2012).

Acknowledgments Development of the BASICS database was supported by the Department of Neurology, University Medical Centre Utrecht, The Netherlands.

Conflicts of interest All authors report no disclosures.
Open Access This article is distributed under the terms of the Creative Commons Attribution License which permits any use, distribution, and reproduction in any medium, provided the original author(s) and the source are credited.

\section{References}

1. Hacke W, Zeumer H, Ferbert A, Brückmann H, del Zoppo GJ (1988) Intra-arterial thrombolytic therapy improves outcome in patients with acute vertebrobasilar occlusive disease. Stroke 19:1216-1222

2. Schonewille WJ, Wijman CA, Michel P, Rueckert CM, Weimar C, Mattle HP, Engelter ST, Tanne D, Muir KW, Molina CA, Thijs V, Audebert H, Pfefferkorn T, Szabo K, Lindsberg PJ, de Freitas G, Kappelle LJ, Algra A; on behalf of the BASICS study group (2009) Treatment and outcomes of acute basilar artery occlusion in the Basilar Artery International Cooperation Study (BASICS): a prospective registry study. Lancet Neurol 8:724-730

3. Brandt T, von Kummer R, Müller-Küppers M, Hacke W (1996) Thrombolytic therapy of acute basilar artery occlusion. Variables affecting recanalization and outcome. Stroke 27:875-881

4. Schonewille WJ, Algra A, Serena J, Molina CA, Kappelle LJ (2005) Outcome in patients with basilar artery occlusion treated conventionally. J Neurol Neurosurg Psychiatry 76:1238-1241

5. Goldmakher GV, Camargo EC, Furie KL, Singhal AB, Roccatagliata L, Halpern EF, Chou MJ, Biagini T, Smith WS, Harris GJ, Dillon WP, Gonzalez RG, Koroshetz WJ, Lev MH (2009) 
Hyperdense basilar artery sign on unenhanced CT predicts thrombus and outcome in acute posterior circulation stroke. Stroke 40:134-139

6. Ezaki Y, Tsutsumi K, Onizuka M, Kawakubo J, Yagi N, Shibayama A, Toba T, Koga H, Miyazaki H (2003) Retrospective analysis of neurological outcome after intra-arterial thrombolysis in basilar artery occlusion. Surg Neurol 60:423-429

7. Sairanen T, Strbian D, Soinne L, Silvennoinen H, Salonen O, Artto V, Koskela I, Häppölä O, Kaste M, Lindsberg PJ; Helsinki Stroke Thrombolysis Registry (HSTR) Group (2011) Intravenous thrombolysis of basilar artery occlusion: predictors of recanalization and outcome. Stroke 42:2175-2179
8. Nagel S, Schellinger PD, Hartmann M, Juettler E, Huttner HB, Ringleb P, Schwab S, Köhrmann M (2009) Therapy of acute basilar artery occlusion: intraarterial thrombolysis alone vs bridging therapy. Stroke 40:140-146

9. Schonewille WJ, Wijman CAC, Michel P, Algra A, Kappelle LJ, on behalf of the BASICS study group (2007) The Basilar Artery International Cooperation Study (BASICS). Int $\mathrm{J}$ Stroke 2:220-223

10. Greenland S, Finkle WD (1995) A critical look at methods for handling missing covariates in epidemiologic regression analyses. Am J Epidemiol 142:1255-1264 